\title{
Lumbar Kinematics, Functional Disability and Fear Avoidance Beliefs Among Adults with Nonspecific Chronic Low Back Pain
}

Nancy G. Jette, ${ }^{1,2}$ Yi L. Lim, ${ }^{1,3}$ Hui L. Lim, ${ }^{1}$ Sabarul A. Mokhtar, ${ }^{4}$ Kok B. Gan, ${ }^{5}$ "Devinder K. A. Singh ${ }^{1}$

$$
\begin{aligned}
& \text { الحركات في منطقة الفقرات القطنية أسفل الظهر والعجز الوظائفي والمعتقدات } \\
& \text { المتعلقة بتجنب الخوف بين البالغين الذين يعانون من آلام مزمنة وغير محددة }
\end{aligned}
$$

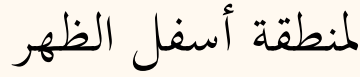

نانسي جورج جيتي، يي لين ليم، هوي لينج ليم، سابارول أفيان مختار، كوك بنج جان، ديفيندر كور أجيت سينج

ABSTR AC T: Objectives: This study aimed to examine correlations between lumbar kinematics, functional disability and fear avoidance beliefs among adults with nonspecific chronic low back pain (LBP). Methods: This crosssectional study was conducted between March and December 2014. A total of 32 adults diagnosed with nonspecific chronic LBP were recruited from outpatients attending either an orthopaedic clinic at a university hospital or a private physiotherapy clinic in Malaysia. Lumbar kinematics were measured using sensors attached at the first lumbar (L1) and second sacral (S2) vertebrae levels. The Oswestry Disability Index (ODI) and Fear-Avoidance Beliefs Questionnaire (FABQ) were used to assess degree of functional disability and fear avoidance beliefs, respectively. Results: For maximum range of motion, positive correlations were observed between ODI scores and right lateral flexion and right rotation $(P=0.01$ each), although there was a negative correlation with left rotation $(P=0.03)$. With maximum angular velocity, ODI scores were positively correlated with right and left lateral flexion L1 $(P=0.01$ and $<0.01$, respectively) but negatively correlated with left lateral flexion $\mathrm{L} 2(P=0.04)$. Regarding minimum angular velocity, ODI scores were positively correlated with left lateral flexion $\mathrm{S} 2(P<0.01)$ but negatively correlated with right and left lateral flexion L1 $(P=0.02$ each), right rotation L1 $(P=0.02)$ and left rotation S2 $(P=0.01)$. No significant correlations were found between lumbar kinematics and FABQ scores. Conclusion: These findings suggest that certain lumbar kinematic parameters are correlated with functional disability, but not with fear avoidance beliefs.

Keywords: Low Back Pain; Lumbar Vertebrae; Kinematics; Disability Evaluation; Fear.

$$
\begin{aligned}
& \text { الملخص: الهذف: هدفت هذه الدراسة إلى فحص العلاقات المتبادلة بين الحركات في منطقة الفقرات القطنية أسفل الظهر والعجز الوظة الفائفي }
\end{aligned}
$$

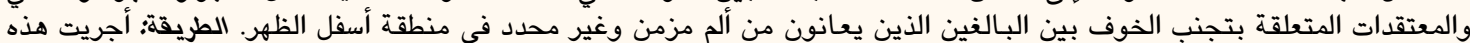




\section{Advances in KNOWLEDGE}

The current study identified significant correlations between several lumbar kinematic parameters and functional disability as determined using the Oswestry Disability Index among adults with nonspecific chronic low back pain (LBP). However, no correlations were observed between lumbar kinematic parameters and fear avoidance beliefs.

\section{Application to Patient Care}

The findings of this study indicate that both lumbar kinematics and functional impairment should be taken into consideration during the assessment and management of adults with nonspecific chronic LBP.

L OW BACK PAIN (LBP) IS THE TERM USED TO indicate lumbosacral pain originating between gluteal fold. ${ }^{1}$ It is a global health problem with a lifetime prevalence of over $80 \%$; moreover, $11-12 \%$ of adults with LBP suffer from physical disabilities. ${ }^{1,2}$ Acute LBP is defined as pain that occurs suddenly after a minimum of six months without pain and lasting for six weeks or less, whereas chronic LBP denotes periodic pain persisting for more than three months with increased risk of recurrence. ${ }^{1,2}$ The prevalence of chronic LBP is approximately $23 \% .^{2}$ In general, acute LBP has an organic pathology; however, biopsychosocial factors that can predispose an individual to chronic LBP are often present at the time of onset. ${ }^{3}$

Lumbar kinematic measurements include an assessment of the range of motion (ROM), movement velocity and acceleration of the lumbar spine. ${ }^{4}$ These variables may assist in the identification of adults at risk of LBP as adults with chronic LBP have shown variations in lumbar biomechanical parameters, including reduced ROM, velocity and acceleration., However, the current focus on structural and biomechanical abnormalities is inadequate to explain chronic LBP and its associated disabilities, with previous research supporting the inclusion of biopsychosocial factors. ${ }^{7,8}$ Studies have shown an association between pain-related fear of movement and reduced lumbar flexion among adults with chronic LBP and indicated that pain-related fear of movement can lead to disabilities. ${ }^{9-12}$ However, it is unclear whether adults with LBP who have pain-related fear of movement deliberately avoid movements of increased velocity and acceleration.

Pain-related fear of movement can be measured using the Fear-Avoidance Beliefs Questionnaire (FABQ), which quantifies an individual's fear of pain as a result of alterations in behaviour to avoid pain. ${ }^{8}$ A positive correlation has been reported between FABQ scores and disability measures; however, inconsistent results have been found regarding the relationship between pain-related fear and decreased activity. ${ }^{12,13}$ The Oswestry Disability Index (ODI) has been deemed suitable for determining an individual's disability in relation to chronic pain, with higher scores indicating greater levels of disability.14,15 Nevertheless, findings of correlations between lumbar ROM measurements and functional impairment in adults with chronic LBP have not been consistent. ${ }^{16}$ Although a weak relationship between flexion ROM and disability in adults with LBP has been found, ROM and the angular velocity of flexion and extension movements have shown an inconsistent relationship with ODI scores.,17 Overall, there are limited and conflicting data regarding the correlations between lumbar kinematics and functional disability and fear avoidance. Further studies on this topic may assist clinicians in the management and care of adults with chronic LBP. The current study therefore aimed to examine the correlation between lumbar kinematics, functional disability and fear avoidance beliefs among adults with chronic LBP.

\section{Methods}

This cross-sectional study was conducted between March and December 2014. A total of 32 adults with chronic LBP persisting for more than three months were recruited from a list of outpatients at either an orthopaedic clinic at the Pusat Perubatan Universiti Kebangsaan Malaysia Hospital, Kuala Lumpur, Malaysia, or a private physiotherapy clinic in Petaling Jaya, Malaysia. The inclusion criteria included outpatients between 20-45 years old with pain originating between the lower ribs and inferior gluteal fold who had been diagnosed by a doctor as having chronic LBP. Patients were excluded from the study if they were currently taking any medications or if they had referred or radicular pain, overt neurological signs (i.e. sensory deficits or motor paralysis), psychological illnesses or "red-flag" disorders (e.g. neoplasms, inflammatory disease, fractures or infections). Women who were pregnant were also excluded. A power analysis for a bivariate normal model was performed using G*Power software, Version 3.1.9.2 (Heinrich Heine University, Dusseldorf, Germany); this indicated that the sample size was sufficient for the purposes of the study (effect size $=0.50$; power $=0.80 ; P<0.05) .{ }^{18}$ 
Table 1: Demographic characteristics, degree of functional disability* and fear avoidance belief ${ }^{\dagger}$ scores among adults with chronic low back pain $(\mathrm{N}=32)$

Variable
Gender, $\mathbf{n}(\%)$
$\quad$ Male
$\quad 13(40.6)$
$\quad$ Female
Age in years
VAS score
BMI in kg/m ${ }^{2}$
Employment status, $\mathbf{n}(\%)$
$\quad$ Unemployed

Lumbar kinematic parameters, including lumbar ROM, velocity and acceleration, were measured using an inertial measurement system (MTx human motion tracker, Xsens Technologies B.V., Enschede, Netherlands). This system provides an accurate and drift-free $360^{\circ}$ view with a three-dimensional spinal range of movement and coupled motion measurements. The first lumbar (L1) and second sacral (S2) spinous processes were identified by palpating the spine when the participant was in a standing position. Two sensors set at $50 \mathrm{~Hz}$ were attached perpendicularly to each other and the spinous processes of the $\mathrm{L} 1$ and S2 vertebrae and secured to the trunk with an elastic strap. Participants were then requested to move to their full ROM, while limiting pelvic movements as much as possible. The ROM of six physiological movements was then obtained by calculating the relative angles between the two sensors using a direction cosine matrix that transforms vectors in the body frame to reference frame analysis (MATLAB software, MathWorks Inc., Natick, Massachusetts, USA). Each participant was requested to perform three repetitions of flexion, extension, lateral flexion (left and right) and rotation (left and right) with their feet shoulder-width apart and knees extended. The averages of the three measurements were taken as ROM and velocity results. Participants were given a
Table 2: Mean maximum range of motion variables among adults with chronic low back pain $(\mathrm{N}=32)$

$\begin{array}{lc}\text { ROM in degrees } & \text { Mean } \pm \text { SD } \\ \text { Flexion } & 37.52 \pm 9.25 \\ \text { Extension } & 9.33 \pm 7.61 \\ \text { Right lateral flexion } & 13.72 \pm 10.23 \\ \text { Left lateral flexion } & 11.67 \pm 13.62 \\ \text { Right rotation } & 8.23 \pm 12.76 \\ \text { Left rotation } & 11.05 \pm 11.77\end{array}$

$R O M=$ range of motion; $S D=$ standard deviation

demonstration of this process before official recording of the data began.

The sociodemographic characteristics of the participants were obtained, including age, gender and employment status. Weight and height were measured to calculate body mass index (BMI). Back pain was evaluated using a visual analogue scale (VAS), which has a $10 \mathrm{~cm}$ horizontal line numbered from 0 to 10 with 0 signifying no pain, 5 signifying moderate pain and 10 signifying the worst possible pain. ${ }^{19}$ Participants were required to mark the point on the scale that they felt represented their current pain status. The 10-item ODI questionnaire was used to quantify the severity of disability for each participant, with a score between 0-5 being assigned for each of the following items: pain intensity, personal care, lifting, walking, sitting, standing, sleeping, sex life, social life and travelling. ${ }^{14}$ The total score of the 10-item ODI questionnaire was recorded as a percentage. Fear avoidance beliefs were assessed using the 5-item physical activity (FABQ-PA) and 11-item work (FABQ-W) subscales of the FABQ, with scores ranging on a Likert scale of $0-6 .{ }^{8}$ A score of 6 was taken to denote the highest level of fear avoidance belief. ${ }^{8}$ Both the ODI and FABQ questionnaires were completed by the researchers in English during interviews with the participants.

All data analysis was performed using the Statistical Package for the Social Sciences (SPSS), Version 20 (IBM Corp., Chicago, Illinois, USA). A Shapiro-Wilk test indicated that most of the kinematic variables were not normally distributed; thus, Spearman's rank correlation coefficient was used to determine correlations between the variables. A $P$ value of $<0.05$ was considered to be statistically significant.

Ethical approval for this study was obtained from the Secretariat for Research \& Ethics of the Universiti Kebangsaan Malaysia, Kuala Lumpur (UKM \#1.5.3.5/244/NN-147-2013). All participants were provided with written and verbal information about the study procedures and gave informed verbal consent for participation. 
Table 3: Mean minimum and maximum angular velocity variables among adults with chronic low back pain $(\mathrm{N}=32)$

\begin{tabular}{|c|c|c|}
\hline \multirow{2}{*}{$\begin{array}{l}\text { Angular velocity } \\
\text { in degrees/second }\end{array}$} & \multicolumn{2}{|c|}{ Mean \pm SD } \\
\hline & Minimum & Maximum \\
\hline \multicolumn{3}{|l|}{ Flexion } \\
\hline L1 & $-84.22 \pm-25.78$ & $83.65 \pm-26.93$ \\
\hline $\mathrm{S} 2$ & $-59.59 \pm-20.05$ & $56.72 \pm-20.63$ \\
\hline \multicolumn{3}{|l|}{ Extension } \\
\hline L1 & $-30.37 \pm-25.78$ & $33.23 \pm-18.33$ \\
\hline S2 & $-22.35 \pm-21.20$ & $21.77 \pm-16.62$ \\
\hline \multicolumn{3}{|l|}{ Right lateral flexion } \\
\hline L1 & $-17.76 \pm-10.31$ & $17.76 \pm-10.89$ \\
\hline S2 & $-12.61 \pm-5.16$ & $12.03 \pm-5.16$ \\
\hline \multicolumn{3}{|l|}{ Left lateral flexion } \\
\hline L1 & $-17.76 \pm-10.31$ & $18.33 \pm-9.74$ \\
\hline S2 & $-12.03 \pm-4.58$ & $12.03 \pm-5.16$ \\
\hline \multicolumn{3}{|l|}{ Right rotation } \\
\hline L1 & $-25.21 \pm-43.54$ & $23.49 \pm-39.53$ \\
\hline S2 & $-20.63 \pm-42.40$ & $18.91 \pm-38.39$ \\
\hline \multicolumn{3}{|l|}{ Left rotation } \\
\hline L1 & $-8.02 \pm-4.58$ & $14.32 \pm-14.32$ \\
\hline S2 & $-8.59 \pm-6.88$ & $10.31 \pm-9.74$ \\
\hline \multicolumn{3}{|c|}{$\begin{array}{l}L 1=\text { first lumbar vertebra level; } S 2=\text { second sacral vertebra level; } \\
S D=\text { standard deviation. }\end{array}$} \\
\hline
\end{tabular}

The sociodemographic characteristics and mean ODI and FABQ scores of the participants are shown in Table 1. The mean lumbar ROM for flexion and extension was $37.52 \pm 9.25$ degrees and $9.33 \pm 7.61$ degrees, respectively. Mean rotation and lateral flexion were between 11.67-13.72 degrees and 8.23-11.05 degrees, respectively [Table 2]. Table 3 depicts the mean minimum and maximum angular velocity measurements.

There were significant moderate positive correlations between ODI scores and the right lateral flexion and right rotation ( $P=0.01$ each) variables of maximum ROM, the right and left lateral flexion L1 $(P=0.01$ and $<0.01$, respectively) variables of maximum angular velocity and the left lateral flexion S2 $(P<0.01)$ variable of minimum angular velocity. Significant weak-to-moderate negative correlations were observed between ODI scores and the left rotation $(P=0.03)$ variable of maximum ROM, the left lateral flexion S2 $(P=0.04)$ variable of maximum angular velocity and the right and left lateral flexion L1 $(P=0.02$ each $)$, right rotation L1 $(P=0.02)$ and left rotation S2 $(P=0.01)$ variables of minimum angular velocity. There were no significant correlations between lumbar kinematics and either FABQ-PA or FABQ-W scores [Table 4].

\section{Discussion}

This study aimed to examine potential correlations between lumbar kinematics, functional disability and fear avoidance beliefs among adults with chronic LBP. However, only functional disability was found to be significantly correlated with certain lumbar kinematic parameters, suggesting that greater perceived functional disability was correlated to a decrease or increase in certain aspects of lumbar ROM and angular velocity. Using an electrogoniometer and torsiometer, Bible et al. previously reported mean full active ROM measurements for flexion (54.6 degrees), extension (26.6 degrees), left and right lateral bending (17.5-19.5 degrees) and left and right axial rotation (16.7-17.6 degrees) for adults without LBP. ${ }^{20}$ In comparison, participants in the current study had lower lumbar ROM measurements, with approximately $30 \%$ reduced flexion and rotation, $65 \%$ reduced extension and $35 \%$ reduced rotation. These differences in findings may be due to variations in measurement instruments and study protocols. However, it is noteworthy that extension ROM was the most limited movement in the current study, followed by rotation and side flexion.

In the current study, mean maximum right lateral flexion and right rotation variables of ROM had a positive correlation with ODI scores, whereas there was a negative correlation between left rotation and ODI scores. These results demonstrate an inconsistent correlation between lumbar movements and disability. Clinically, these results are acceptable as both declined and increased mobility may be related to functional ability. ${ }^{21}$ In a previous study, Parks et al. concluded that the association between lumbar motions and functional ability was either weak or absent. ${ }^{22}$ Moreover, a negative correlation between ODI and left rotation ROM has also been described in an earlier report. ${ }^{23}$ Movement impairment among adults with chronic LBP may be due to an associated cocontraction of the lumbar-pelvic muscles and muscle spasms which can lead to limited motion and injury. ${ }^{24}$ On the other hand, hypermobility may also exist in certain spinal segments, causing spinal instability and impaired neuromuscular control, eventually affecting an individual's ability to function normally. ${ }^{25}$ 
Table 4: Correlations between lumbar kinematic variables and functional disability* and fear avoidance beliefs ${ }^{\dagger}$ among adults with chronic low back pain $(\mathrm{N}=32)$

\begin{tabular}{|c|c|c|c|c|c|c|}
\hline \multirow[t]{2}{*}{ Variable } & \multicolumn{2}{|c|}{ ODI score } & \multicolumn{2}{|c|}{$\begin{array}{c}\text { FABQ-PA } \\
\text { score }\end{array}$} & \multicolumn{2}{|c|}{$\begin{array}{l}\text { FABQ-W } \\
\text { score }\end{array}$} \\
\hline & rs & $\begin{array}{c}P \\
\text { value }\end{array}$ & rs & $\begin{array}{c}P \\
\text { value }\end{array}$ & rs & $\begin{array}{c}P \\
\text { value }\end{array}$ \\
\hline \multicolumn{7}{|c|}{ Maximum ROM in degrees } \\
\hline Flexion & 0.07 & 0.72 & -0.03 & 0.86 & -0.22 & 0.23 \\
\hline Extension & 0.10 & 0.60 & 0.00 & 0.98 & -0.16 & 0.39 \\
\hline $\begin{array}{l}\text { Right } \\
\text { lateral } \\
\text { flexion }\end{array}$ & 0.48 & $0.01^{\ddagger}$ & -0.11 & 0.55 & -0.16 & 0.40 \\
\hline $\begin{array}{l}\text { Left } \\
\text { lateral } \\
\text { flexion }\end{array}$ & -0.33 & 0.07 & -0.35 & 0.05 & -0.04 & 0.82 \\
\hline $\begin{array}{l}\text { Right } \\
\text { rotation }\end{array}$ & 0.48 & $0.01^{\neq}$ & 0.04 & 0.83 & -0.11 & 0.56 \\
\hline $\begin{array}{l}\text { Left } \\
\text { rotation }\end{array}$ & -0.39 & $0.03^{\ddagger}$ & -0.29 & 0.11 & -0.21 & 0.25 \\
\hline
\end{tabular}

Maximum angular velocity in degrees/second

Flexion

$\begin{array}{lllllll}\text { L1 } & 0.10 & 0.57 & -0.09 & 0.63 & -0.18 & 0.34 \\ \text { S2 } & 0.15 & 0.40 & -0.17 & 0.35 & 0.22 & 0.23 \\ \text { Extension } & & & & & & \\ \text { L1 } & -0.16 & 0.37 & 0.01 & 0.95 & -0.34 & 0.06 \\ \text { S2 } & -0.31 & 0.09 & -0.09 & 0.64 & -0.24 & 0.20\end{array}$

Right lateral flexion

$\begin{array}{lcccccc}\text { L1 } & 0.44 & 0.01^{\ddagger} & -0.05 & 0.79 & -0.13 & 0.47 \\ \text { S2 } & -0.28 & 0.12 & -0.12 & 0.52 & 0.13 & 0.49 \\ \text { Left lateral flexion } & & & & & \\ \text { L1 } & 0.52 & <0.01^{\ddagger} & 0.07 & 0.72 & -0.18 & 0.32 \\ \text { S2 } & -0.37 & 0.04^{\ddagger} & -0.12 & 0.52 & -0.08 & 0.69 \\ \text { Right rotation } & & & & & & \\ \text { L1 } & 0.26 & 0.15 & -0.12 & 0.50 & -0.25 & 0.16 \\ \text { S2 } & 0.34 & 0.06 & -0.10 & 0.60 & -0.10 & 0.60 \\ \text { Left rotation } & & & & & & \\ \text { L1 } & & & & & & \\ \text { S2 } & 0.24 & 0.19 & -0.19 & 0.30 & -0.06 & 0.76\end{array}$

Minimum angular velocity in degrees/second

Flexion

$\begin{array}{lllllll}\text { L1 } & 0.06 & 0.76 & 0.17 & 0.35 & 0.20 & 0.27 \\ \text { S2 } & 0.19 & 0.30 & 0.20 & 0.28 & 0.11 & 0.55\end{array}$

Extension

$\begin{array}{lllllll}\text { L1 } & -0.01 & 0.95 & 0.08 & 0.65 & 0.27 & 0.14 \\ \text { S2 } & 0.11 & 0.55 & 0.01 & 0.96 & 0.20 & 0.28\end{array}$

\section{Right lateral flexion}

$\begin{array}{lllllll}\text { L1 } & -0.42 & 0.02^{\ddagger} & -0.02 & 0.93 & 0.10 & 0.58\end{array}$

$\begin{array}{lllllll}\mathrm{S} 2 & 0.26 & 0.15 & 0.08 & 0.68 & 0.09 & 0.62\end{array}$

Left lateral flexion

$\begin{array}{lllllll}\text { L1 } & -0.42 & 0.02^{\ddagger} & -0.01 & 0.97 & 0.13 & 0.50\end{array}$

$\begin{array}{lllllll}\text { S2 } & 0.51 & <0.01^{\ddagger} & 0.16 & 0.37 & -0.15 & 0.41\end{array}$

Right rotation

$\begin{array}{lllllll}\text { L1 } & -0.42 & 0.02^{\ddagger} & 0.05 & 0.80 & 0.28 & 0.13\end{array}$

$\begin{array}{lllllll}\text { S2 } & -0.29 & 0.11 & 0.11 & 0.56 & 0.20 & 0.27\end{array}$

Left rotation

$\begin{array}{lllllll}\text { L1 } & 0.25 & 0.16 & 0.30 & 0.09 & 0.07 & 0.72\end{array}$

$\begin{array}{lllllll}\text { S2 } & -0.47 & 0.01^{\ddagger} & 0.03 & 0.88 & 0.11 & 0.54\end{array}$

$O D I=$ Oswestry Disability Index; FABQ-PA = physical activity subscale of the Fear-Avoidance Beliefs Questionnaire; FABQ-W = work subscale of the Fear-Avoidance Beliefs Questionnaire; $r$ s = Spearman's rank correlation coefficient; $R O M=$ range of motion; $L 1$ = first lumbar vertebra level; S2 = second sacral vertebra level.

"Functional disability was assessed using the Oswestry Disability Index. ${ }^{14}$

${ }^{\dagger}$ Fear avoidance beliefs were assessed using the Fear-Avoidance Beliefs Questionnaire. ${ }^{8}$

${ }^{\ddagger}$ Significant at $P<0.05$.

As with ROM, inconsistent results were also observed in the current study with regards to lumbar velocity. The authors of the current study speculate that this may be due to the complex relationship of lumbar kinematics with functional impairment. Other factors may have influenced the results, such as limb dominance, laterality of pain, level of pain and disability. Adults with LBP have been found to move more slowly compared to healthy individuals. ${ }^{26}$ It is also noteworthy that the mean ODI score of participants in the current study indicated minimal disability (19.2\%), while the mean VAS score $(2 / 10)$ suggested only mild-to-moderate disability. ${ }^{14}$ Thus, the results of the present study could have been influenced by the lack of severity of LBP symptoms among the participants. In addition, asymmetries in lumbar motion have been noted among adults without LBP which were unrelated to any limitations and were believed to be derived from daily habitual movements. ${ }^{27}$

Pain-related fear is believed to be an important factor in determining disability in chronic LBP, rather than pain or physical impairment alone. ${ }^{22}$ The present study found that lumbar kinematic variables were not associated with FABQ-PA or FABQ-W scores. Similarly, Demoulin et al. reported that painrelated fear measures were not significantly related to the physical capacity of the spine. ${ }^{28}$ However, these findings are contradictory to those of earlier studies reporting associations between physical ability and 
fear avoidance beliefs. ${ }^{9,11,29}$ In one study, Geisser et al. observed a significant correlation between pain-related fear and decreased lumbar flexion among participants with chronic LBP. ${ }^{9}$ Vaisy et al. reported that ROM and angular velocity were associated with psychological characteristics, including fear of movement. ${ }^{11}$ Grotle et al. found that fear avoidance beliefs were significantly related to disability after controlling for sociodemographic, pain-related and clinical variables and excluding distress variables. ${ }^{30}$ Another study found that a combination of psychological factors, including fear avoidance beliefs, anxiety and pain catastrophising, determined functional disability in adults with chronic LBP. ${ }^{31}$ Nevertheless, other sociodemographic and psychosocial factors such as income, education level, type of management received, selfefficacy and motivation may need to be accounted for when considering a relationship between pain-related fear of movement and functional ability.

The findings of the present study add to existing controversy in the literature regarding the correlation between lumbar motion, functional ability and fear avoidance beliefs. Differences in findings may be due to inter-study variations in measurement instruments, protocols, participant selection and analysis systems. Despite this, the results of the current study may be of interest to clinicians in the assessment and management of adults with nonspecific chronic LBP. It is important to note that observation of lumbar ROM through visual estimations may not show small differences. However, measurements of higher order kinematics, such as movement velocity and acceleration, may not be feasible in clinical settings as they often require costly instrumentation. Physiotherapists should provide individually tailored exercises focusing on lumbar rotation and lateral flexion movements as well as lumbar extension when treating adults with nonspecific chronic LBP.

There are a few limitations to this study. Firstly, the sample size was limited and confined to adults with nonspecific chronic LBP. Secondly, data regarding quality of movement, specific locations of pain and range of pain were not analysed. Therefore, the results of this study cannot be generalised to other types of LBP with symptoms that include unilateral pain, hypomobility or hypermobility. Further studies are required assessing lumbar kinematics among patients with different types of LBP in comparison to a control group. ${ }^{32}$ There is also a need for future research to examine the relationship between lumbar kinematics and sustained prolonged functional activities among adults with nonspecific chronic LBP.

\section{Conclusion}

The results of this study suggest that certain components of rotation and lateral flexion are correlates of functional disability, but not fear avoidance beliefs. Lumbar rotation and lateral flexion movements should therefore be emphasised in addition to lumbar extension during rehabilitation therapy for adults with nonspecific chronic LBP. In addition, both lumbar kinematics and functional impairment should be taken into consideration in the assessment and management of adults with nonspecific chronic LBP.

\section{CONFLICT OF INTEREST}

The authors declare no conflicts of interest.

\section{FUNDING}

This study was funded by a grant from the Ministry of Higher Education, Malaysia, through Universiti Kebangsaan Malaysia (\#ERGS/1/2012/SKK10/UKM/02/2).

\section{References}

1. Hoy D, Brooks P, Blyth F, Buchbinder R. The epidemiology of low back pain. Best Pract Res Clin Rheumatol 2010; 24:769-81. doi: 10.1016/j.berh.2010.10.002

2. Balagué F, Mannion AF, Pellisé F, Cedraschi C. Non-specific low back pain. Lancet 2012; 379:482-91. doi: 10.1016/S01406736(11)60610-7.

3. Koho P, Aho S, Watson P, Hurri H. Assessment of chronic pain behaviour: Reliability of the method and its relationship with perceived disability, physical impairment and function. J Rehabil Med 2001; 33:128-32. doi: 10.1080/165019701750165970.

4. Lehman GJ. Biomechanical assessments of lumbar spinal function: How low back pain sufferers differ from normals Implications for outcome measures research: Part I - Kinematic assessments of lumbar function. J Manipulative Physiol Ther 2004; 27:57-62. doi: 10.1016/j.jmpt.2003.11.007.

5. Williams JM, Haq I, Lee RY. A novel approach to the clinical evaluation of differential kinematics of the lumbar spine. Man Ther 2013; 18:130-5. doi: 10.1016/j.math.2012.08.003.

6. Trost Z. Pain-related fear, pain and harm appraisal, and kinematic avoidance among healthy participants following delayed onset muscle soreness. PhD Thesis. Athens, Ohio, USA: Ohio University, 2010.

7. Leeuw M, Goossens ME, Linton SJ, Crombez G, Boersma K, Vlaeyen JW. The fear-avoidance model of musculoskeletal pain: Current state of scientific evidence. J Behav Med 2007; 30:77-94. doi: 10.1007/s10865-006-9085-0.

8. Waddell G, Newton M, Henderson I, Somerville D, Main CJ. A Fear-Avoidance Beliefs Questionnaire (FABQ) and the role of fear-avoidance beliefs in chronic low back pain and disability. Pain 1993; 52:157-68. doi: 10.1016/0304-3959(93)90127-B.

9. Geisser ME, Haig AJ, Wallbom AS, Wiggert EA. Pain-related fear, lumbar flexion, and dynamic EMG among persons with chronic musculoskeletal low back pain. Clin J Pain 2004; 20:61-9. doi: 10.1097/00002508-200403000-00001. 
10. Thomas JS, France CR, Lavender SA, Johnson MR. Effects of fear of movement on spine velocity and acceleration after recovery from low back pain. Spine (Phila Pa 1976) 2008; 33:564-70. doi: 10.1097/BRS.0b013e3181657f1a.

11. Vaisy M, Gizzi L, Petzke F, Consmüller T, Pfingsten M, Falla D. Measurement of lumbar spine functional movement in low back pain. Clin J Pain 2015; 31:876-85. doi: 10.1097/ AJP.0000000000000190.

12. George SZ, Fritz JM, McNeil DW. Fear-avoidance beliefs as measured by the Fear-Avoidance Beliefs Questionnaire: Change in fear-avoidance beliefs questionnaire is predictive of change in self-report of disability and pain intensity for patients with acute low back pain. Clin J Pain 2006; 22:197-203. doi: 10.1097/01.ajp.0000148627.92498.54.

13. van Weering $M$, Vollenbroek-Hutten MM, Kotte EM, Hermens HJ. Daily physical activities of patients with chronic pain or fatigue versus asymptomatic controls: A systematic review. Clin Rehabil 2007; 21:1007-23. doi: 10.1177/0269215 507078331.

14. Fairbank JC, Pynsent PB. The Oswestry Disability Index. Spine (Phila Pa 1976) 2000; 25:2940-52. doi: 10.1097/00007632200011150-00017.

15. Vianin M. Psychometric properties and clinical usefulness of the Oswestry Disability Index. J Chiropr Med 2008; 7:161-3. doi: 10.1016/j.jcm.2008.07.001.

16. Nattrass CL, Nitschke JE, Disler PB, Chou MJ, Ooi KT. Lumbar spine range of motion as a measure of physical and functional impairment: An investigation of validity. Clin Rehabil 1999; $13 \cdot 211-18$.

17. Vlaeyen JW, Linton SJ. Fear-avoidance and its consequences in chronic musculoskeletal pain: A state of the art. Pain 2000; 85:317-32. doi: 10.1016/S0304-3959(99)00242-0.

18. Faul F, Erdfelder E, Buchner A, Lang AG. Statistical power analyses using $\mathrm{G}^{*}$ Power 3.1: Tests for correlation and regression analyses. Behav Res Methods 2009; 41:1149-60. doi: 10.3758/ BRM.41.4.1149.

19. Bijur PE, Silver W, Gallagher EJ. Reliability of the visual analog scale for measurement of acute pain. Acad Emerg Med 2001; 8:1153-7. doi: 10.1111/j.1553-2712.2001.tb01132.x.

20. Bible JE, Biswas D, Miller CP, Whang PG, Grauer JN. Normal functional range of motion of the lumbar spine during 15 activities of daily living. J Spinal Disord Tech 2010; 23:106-12. doi: 10.1097/BSD.0b013e3181981823.

21. Key J. Back Pain: A Movement Problem - A clinical approach incorporating relevant research and practice. London, UK: Churchill Livingstone, 2010. Pp. 152-63. doi: 10.1016/B978-07020-3079-6.00004-6.
22. Parks KA, Crichton KS, Goldford RJ, McGill SM. A comparison of lumbar range of motion and functional ability scores in patients with low back pain: Assessment for range of motion validity. Spine (Phila Pa 1976) 2003; 28:380-4. doi: 10.1097/01. BRS.0000048466.78077.A6.

23. Beazell JR, Mullins M, Grindstaff TL. Lumbar instability: An evolving and challenging concept. J Man Manip Ther 2010; 18:9-14. doi: 10.1179/106698110X12595770849443.

24. Michel A, Kohlmann T, Raspe H. The association between clinical findings on physical examination and self-reported severity in back pain: Results of a population-based study. Spine (Phila Pa 1976) 1997; 22:296-303. doi: 10.1097/00007632199702010-00013.

25. O'Sullivan P. Diagnosis and classification of chronic low back pain disorders: Maladaptive movement and motor control impairments as underlying mechanism. Man Ther 2005; 10:242-55. doi: 10.1016/j.math.2005.07.001.

26. Simmonds MJ, Lee CE, Etnyre BR, Morris GS. The influence of pain distribution on walking velocity and horizontal ground reaction forces in patients with low back pain. Pain Res Treat 2012; 2012:214980. doi: 10.1155/2012/214980.

27. Gomez TT. Symmetry of lumbar rotation and lateral flexion range of motion and isometric strength in subjects with and without low back pain. J Orthop Sports Phys Ther 1994; 19:42-8. doi: 10.2519/jospt.1994.19.1.42.

28. Demoulin C, Huijnen IPJ, Somville PR, Grosdent S, Salamun I, Crielaard JM, et al. Relationship between different measures of pain-related fear and physical capacity of the spine in patients with chronic low back pain. Spine J 2013; 13:1039-47. doi: 10.1016/j.spinee.2013.02.037.

29. Vlaeyen JW, Linton SJ. Fear-avoidance model of chronic musculoskeletal pain: 12 years on. Pain 2012; 153:1144-7. doi: 10.1016/j.pain.2011.12.009.

30. Grotle M, Vøllestad NK, Brox JI. Clinical course and impact of fear-avoidance beliefs in low back pain: Prospective cohort study of acute and chronic low back pain - II. Spine (Phila Pa 1976) 2006; 31:1038-46. doi: 10.1097/01.brs.0000214878.01709.0e.

31. Dubois JD, Abboud J, St-Pierre C, Piché M, Descarreaux M. Neuromuscular adaptations predict functional disability independently of clinical pain and psychological factors in patients with chronic non-specific low back pain. J Electromyogr Kinesiol 2014; 24:550-7. doi: 10.1016/j.jelekin.2014.04.012.

32. Nancy GJ, Singh DK, Nordin NA, Ha TH, Mokhtar SA, Chang $\mathrm{SH}$, et al. Lumbar kinematic pattern among adults with low back pain: A study protocol. J Teknol 2016; 78:101-6. doi: 10.11113/jt.v78.9061 